\title{
Análise da permeabilidade das luvas de látex para procedimento mais utilizadas por alunos da Faculdade de Odontologia da Universidade Federal da Bahia
}

\author{
Nereida Lopes ${ }^{l}$ \\ Natália Prates ${ }^{1}$ \\ Rosângela Rabelo ${ }^{2}$ \\ José Flávio Wanderley Cruz ${ }^{3}$
}

\begin{abstract}
Resumo
Este trabalho teve como objetivo analisar a permeabilidade das luvas de látex para procedimento mais usadas por alunos da Faculdade de Odontologia da Universidade Federal da Bahia. Foram observadas quarenta luvas de duas marcas distintas, as quais, que após duas horas infladas com água corada com violeta de genciana, apresentaram umidade superficial.
\end{abstract}

Palavras-chave: Luvas - Permeabilidade; Biossegurança - Odontologia.

\section{INTRODUÇÃO}

A necessidade do uso de Equipamentos de Proteção Individual (EPI) por profissionais da área de saúde, ou todos aqueles que, em suas atividades profissionais, podem entrar em contato com sangue ou fluidos corporais, foi recomendada por uma publicação do CDC (Center for Disease Control), em 1987. Essa necessidade foi referendada pela ADA (American Dental Association), que dispõe sobre normas e precauçôes universais do controle da infecção para os profissionais da saúde, com a finalidade de diminuir o risco de contaminação por HIV (Human Imunodeficiency Virus), HBV (Hepatite B vírus) e tuberculose, assim como o vírus do herpes (LEAL et al., 2004).
A contaminação por agentes patógenos veiculados por sangue depende da duração e da frequência da exposição do profissional ao sangue de pacientes infectados. $\mathrm{O}$ risco dessa exposição é diretamente influenciado por fatores ambientais, como manipulação de agulhas ou equipamentos contaminados, e da educação em relação ao uso dos EPIs por esses profissionais. O conceito de Medida de Proteção Universal (MPU), pressupooe que todos os pacientes estão potencialmente infectados com agentes patógenos transmitidos pelo sangue ou fluidos do corpo. Quanto à saliva, ela tem se mostrado como o segundo maior veículo de doenças infecto-contagiosas, justificando, assim, a utilização de barreiras mecânicas pelos profissionais da área de saúde.

\footnotetext{
${ }^{1}$ Alunas de Graduação da Faculdade de Odontologia - UFBA.

2 Professor Adjunto I; Mestranda- Faculdade de Odontologia - UFBA.

${ }^{3}$ Professor Adjunto IV; Mestre - Faculdade de Odontologia - UFBA.
} 
Portanto, aos profissionais de saúde é necessário não só o conhecimento dos EPIs, mas, principalmente, o uso habitual desses equipamentos. Porém tal uso está ligado à educação, e essa não pode ser imposta por normas, pois deve, antes de tudo, ser uma busca do próprio homem, tomando como base as noções dos mecanismos de ação desses agentes patógenos, assim como o treinamento, domínio e frequência do uso dos equipamentos de proteção. Dentre os EPIs, as luvas de procedimento em látex ou de vinil são os mais fáceis e práticos meios de proteção individual. Segundo Leal e colaboradores (2004), foi no ano de 1898 que o Dr. Haltead preconizou o uso de luvas para proteção como procedimento ambulatorial, quando da manipulação direta de substâncias químicas. Essa conduta continua sendo considerada uma das razôes do uso desse equipamento de proteção individual para os profissionais da área de saúde, sendo também barreira contra a contaminação e a infecção cruzada dentro do ambiente clínico de atendimento a pacientes.

O uso das luvas de procedimento é comprovadamente eficiente como um dos equipamentos dos EPIs. Portanto, a qualidade do produto oferecido é de fundamental importância. Este trabalho tem a finalidade de avaliar a integridade de luvas de látex mais utilizadas por alunos da Faculdade de Odontologia da Universidade Federal da Bahia.

\section{REVISÃO DE LITERATURA}

As técnicas de biossegurança na prática odontológica envolvem um conjunto de medidas preventivas, compreendendo os princípios do controle de infecção, as práticas ergonômicas no desenvolvimento do exercício da profissão e o controle dos riscos químicos e físicos. Historicamente, a odontologia era praticada sem a observância desses princípios. Com o advento da AIDS na década de 80 , surgiram discussões que envolvem essa temática. A última década foi de grande relevância para a incorporação de um novo comportamento diante das infecçôes por parte dos cirurgióes-dentistas, embora a formação profissional ainda necessite de que seus currículos incorporem novos conceitos, compatíveis com o cenário epidemiológico contemporâneo (RABELO, 2001).

Com o aumento da prevalência de doenças infecto-contagiosas na população, principalmente de soropositivos para hepatite B e HIV, a manutenção de uma barreira mecânica efetiva entre o cirurgião e o paciente tornou-se assunto de grande interesse (FIALA et al., 1993 apud QUEIROZ; RAMOS; BARREIRO, 2002).

A biossegurança, atualmente, é uma preocupação de todos os serviços relacionados à saúde, e, neles inclui-se a Odontologia, visto que o controle de infecção é de importância relevante. A atividade do cirurgião-dentista expõe seus pacientes, sua equipe, ele próprio e seus familiares a um universo microbiano altamente agressivo (SERRATINE; PACHECO; MIERO, 2007).

O principal meio de prevenção contra a transmissão de doenças infecto- contagiosas é o uso adequado dos equipamentos de proteção individuais (EPI), e uma das primeiras medidas observadas pelos pacientes é se o profissional adotou, no controle da infecção, é o uso de luvas (BEZERRA; PINHEIRO, 1999 ).

A utilização de barreiras de proteção, dentre elas as luvas de látex, é indispensável para a segurança de todos os envolvidos em um tratamento odontológico (SERRATINE; PACHECO; MIERO, 2007). No mercado, podemos encontrar dois tipos de luvas de látex: a de procedimento não cirúrgica, considerada como material descartável, e o seu reprocessamento representa um maior risco de contaminação do profissional e da equipe auxiliar (BEZERRA; PINHEIRO, 1999); e as luvas cirúrgicas estéreis, com dispositivos capazes de se justarem ao braço do usuário (AGÊNCIA NACIONAL DE VIGILÂNCIA SANITÁRIA, 2008).

O uso das luvas cirúrgicas de borracha, em substituição às luvas de pano introduzidas por Mikulicz em 1881, teve início no Hospital Johns Hopkins, em 1890. Mas a primeira publicação a respeito do uso rotineiro de luva cirúrgica para prevenção de infecção 
intraoperatória foi feita por Robb (1894 apud CURY, 1999). Desde então, o uso de luvas cirúrgicas é prática consagrada e sistemática nos procedimentos cirúrgicos, principalmente na atualidade, em que há uma crescente preocupação do profissional e dos próprios pacientes com os vírus da hepatite B2 e da AIDS (SIM; DUDLEY, 1988 apud CURY, 1999).

Muitos autores que pesquisaram a permeabilidade das luvas de látex após o contato com materiais dentais concluíram que a manipulação e a exposição a certos materiais, especialmente solventes, trazem um prejuízo significante à integridade das luvas (BEZERRA; PINHEIRO, 1999).

A proteção da barreira tecidual impede a penetração de alguns patógenos e componentes químicos; consequentemente, a capacidade de infectar desses agentes, assim como a toxicidade de uma determinada substância são limitadas, até certo ponto, por essas barreiras. A integridade de membrana e do tecido pode ser quebrada quando eles estão alterados por uma lesão local na célula ou no tecido. A utilização ilimitada de álcoois e detergentes retiram a capa de gordura natural da pele, facilitando e promovendo a formação de rachaduras e lesões, agravadas com cortes e escoriações da pele, o que favorece sobremaneira a formação de solução de continuidade, comum em caso de pessoas com lesôes por hipersensibilidade a determinados produtos químicos. Nesses casos, recomenda-se veementemente a utilização de duas luvas (RABELO, 2001).

Freire e colaboradores (1997) observaram o comportamento dos estudantes de Odontologia, comparado suas opiniōes e seus conhecimentos e sobre biossegurança, que devem ser adotados rotineiramente para proteger as equipes odontológicas e pacientes do perigo da contaminação cruzada. Os resultados indicaram que, de uma maneira geral, houve um bom entendimento no uso dos procedimentos de biossegurança, porém houve um considerável receio em tratar pacientes comprovadamente infectados pelo HIV (BEZERRA; PINHEIRO, 1999).

Serratine, Pacheco e Miero (2007) recomendaram que cada paciente seja considerado como potencialmente portador de uma doença infecciosa e que as medidas de biossegurança sejam rigorosamente cumpridas em todos os procedimentos. Esses procedimentos, quando utilizados em atendimento a pacientes de alto risco ou não, devem ser adotados rotineiramente, com a finalidade de evitar uma infecção direta e cruzada. Entretanto, apesar dos sérios riscos de contágio desses patógenos e da Legislação Brasileira - que, através da Portaria MS 2.616/ 98, determina as normas de biossegurança a serem cumpridas -, muitos profissionais ainda não adotam todas as medidas de proteção disponíveis. Portadores de doenças infecciosas, muitas vezes, desconhecem o fato de estarem infectados, por apresentarem a doença no período de incubação, e, por isso, não podem ser identificados durante a anamnese e no exame clínico (MAGRO FILHO, 1998 apud SERRATINE; PACHECO; MIERO, 2007).

Luvas devem ser utilizadas em todos os procedimentos em que haja contato com mucosas, sangue e saliva. Entretanto, as luvas são barreiras efetivas apenas se sua integridade permanecer intacta (TUCCI, 1996; SERRATINE; PACHECO; MIERO, 2007).

Fay e colaboradores (1995) relataram, em seus estudos, que as luvas quando intactas, funcionam como barreira contra vírus patógenos. Contudo, nenhuma luva de látex é resistente ao corte nem irá prevenir injúrias e perfurações. Quando o risco de perfuração ou rompimento for elevado, deve-se considerar o uso de duas luvas para reduzir os riscos pessoais (BEZERRA; PINHEIRO, 1999).

Durante a prática da Odontologia, ocorre o contato com os tecidos e secreçôes da cavidade bucal, bem como com sangue proveniente das intervenções. Portanto, a variedade de microrganismos existentes nesses locais pode, por diferentes formas de infecção, provocar doenças no profissional, em sua equipe e nos pacientes. Para impedir essas infecções Serratine, Pacheco e Miero (2007) orientaram para o uso de luvas de látex como a primeira barreira de proteção.

As luvas têm três funções principais: reduzem a possibilidade de o profissional se 
infectar com patógenos presentes no sangue e (ou) na saliva dos pacientes, diminuem as chances de o cirurgião-dentista transmitir microrganismos da microbiota própria de suas mãos para os pacientes, e reduzem as possibilidades da transmissão de microrganismos da boca de um paciente para outro, a partir da colonização transitória das mãos do profissional. Entretanto, para que elas exerçam adequadamente suas funções, é necessário que sejam de boa qualidade e não apresentem solução de continuidade que permita a difusão de patógenos (SERRATINE; PACHECO; MIERO, 2007).

Ottis e Cottone (1989 apud BEZERRA; PINHEIRO, 1999) estudaram a prevalência de perfuraçôes em luva de látex descartável durante a rotina do tratamento dental. Os resultados mostraram ser significante a influência da integridade da luva durante o tempo usado. Para manter as condições de barreira, elas devem ser usadas em intervalos inferiores a 2 horas. Destacaram, também, que, durante vinte minutos, por uma única perfuração, podem passar aproximadamente dezenove mil bactérias. Guandalini (1997) relata, em sua pesquisa que, em consequência do longo tempo de permanência em contato com a umidade, as luvas tornam-se uma membrana semipermeável, possibilitando a passagem de microorganismos para o lado interno, facilitando a contaminação do profissional.

Tucci (1996) comparou a qualidade do látex das luvas de várias marcas comerciais, concluindo que, embora todas as luvas avaliadas apresentassem alterações morfológicas, havia variação na qualidade entre as marcas, pois algumas apresentavam somente depressões, enquanto outras não eram homogêneas, apresentando áreas de fragilidade propícias às perfurações.

Melo e Smaha (2002) avaliaram a permeabilidade de luvas de látex sem uso e após um único uso, através do método visual, e comprovaram que $55 \%$ das luvas de procedimentos testadas apresentavam furos após uso único.

Katz, Gobetti e Shipman Jr. (1989) avaliaram a integridade das luvas com corantes fluorescentes através de vários métodos, para detectar defeitos, e concluíram que o uso da técnica de corante fluorescente foi superior em termos de eficiência, quando comparado com outros métodos de detectar defeitos, incluindo inflação de ar e submersão de água.

O iNmetro (1998) analisou 8 marcas de luvas cirúrgicas esterilizadas - 3 importadas e 5 nacionais - e 7 marcas de luvas para procedimento não-cirúrgico não-esterilizadas 6 importadas e uma nacional. A análise das luvas cirúrgicas esterilizadas apresentou um resultado preocupante: das 8 marcas analisadas, somente 3 marcas foram consideradas adequadas em todos os requisitos. As demais marcas não atenderam, pelo menos, a um dos requisitos ensaiados, sendo consideradas não conformes. A análise de luvas para procedimentos nãocirúrgicos não-esterilizadas apresentou um resultado melhor: das 7 marcas analisadas, somente 1 (uma) marca foi considerada nãoconforme. A elevada incidência de não conformidades, em particular no ensaio, foi referente à presença de furos nas luvas testadas.

\section{MATERIAIS E MÉTODO}

A intenção deste trabalho é retratar o panorama real dos produtos testados, sem, no entanto, a qualificação de determinada marca ou empresa específica.

Neste estudo foi avaliada a integridade de luvas de látex para procedimento das marcas comerciais mais utilizadas por alunos do $7^{\circ}, 8^{\circ}$ $9^{\circ}$ e $10^{\circ}$ semestres do curso de Odontologia da UFBA, em atividades ambulatoriais. De acordo com avaliação prévia, observou-se que duas marcas comerciais tinham a preferência dos alunos, e, assim, foram consideradas objeto deste estudo. Foram estudadas as marcas Descarpak ${ }^{\circledR}$ (TOP GLOVE SDN. BHD- Lote PA 50-Abril/ 2007), compondo o Grupo de Teste A (GTA) e Supermax ${ }^{\circledR}$ (SUPERMAX GLOVE MANUFACTURIN SDN. BHD- Lote 020017 082- Agosto /2007), que constituiu o Grupo de Teste B(GTB). Segundo os fabricantes, a validade de uso é de três anos.

Cada grupo teste (GTA e GTB) foi composto por 20 luvas ambidestras, tamanho 
médio (M), escolhidas aleatoriamente. Esses grupos foram subdivididos em dois, identificados com números, formando-se quatro grupos de 10, com um total de 40 luvas, distribuídas da seguinte forma: GTA 1, GTA 2, GTB 3 e GTB 4. Tal divisão teve por finalidade facilitar a análise, feita por um único observador. A presença de rasgos, perfuração visível ou a observação de vazamento imediato da água corada foram os critérios de exclusão para os espécimes utilizados nesta pesquisa.

Cada luva de procedimento em látex foi preenchida com $700 \mathrm{ml}$ de água corada com violeta genciana a $1 \%$, à temperatura ambiente, (metodologia baseada em Bezerra e Pinheiro, 1999). A proposição de $700 \mathrm{ml}$ foi estabelecida por não ter sido feita nenhuma compressão para observação de extravasamento do líquido. As luvas foram, após o seu preenchimento, secas e suspensas individualmente em suporte específico, sendo presas por pressão, sem possibilidade de perfuração ou rasgamento. Assim permaneceram por 2 horas, a uma distância de $1 \mathrm{~m}$ do solo. Sob as luvas, no solo, foram colocadas folhas de papel absorvente, com o intuito de observar possíveis vazamentos, através de manchas no papel. Cada grupo foi observado a cada 30 minutos e registrada, em ficha apropriada, a presença de manchas e/ou deformações no papel.

\section{DISCUSSÃO E RESULTADOS}

A importância que a biossegurança vem exercendo na prática odontológica estimula novas pesquisas que comprovem a eficácia dos métodos de combate à contaminação cruzada. O conhecimento e uso responsável dos equipamentos de proteção individual (EPI) deverão ser observados em todos os procedimentos que envolvam o contato com fluidos corpóreos. A literatura relata trabalhos que buscam avaliar a ação positiva dos EPI, a exemplo das luvas de látex para procedimentos vários. Após duas horas, foram observadas algumas alterações, conforme demonstra a Tabela 1 .

A metodologia empregada foi efetiva para a proposição do nosso trabalho, consoante com Checchi e colaboradores (1992), entre outros, na utilização da água corada para a comprovação da presença de furos em luva de látex, sem, entretanto, a compressão proposta por estes autores para a observação de extravasamento da água. Vários estudos avaliam a presença de perfurações após procedimentos. A presente pesquisa ao avaliar a impermeabilidade das luvas antes de serem utilizadas comprova que porosidades significativas e alterações não visíveis a olho desarmado podem estar presentes, aumentando o risco da contaminação. A permanência da água corada em contato com as luvas por um período de duas horas foi efetiva, quando demonstrou que $100 \%$ das luvas testadas, após esse período de tempo, estavam úmidas. Esse achado confirma os estudos de Guandalini (1997), que ao identificar a permanência das luvas por um longo período em contato com a umidade, revelaram a possibilidade da passagem de fluidos, condição que favorece a contaminação profissional.

$\mathrm{Na}$ embalagem que continha as luvas da marca que representou o GTA, foram encontradas $5(1 \%)$ luvas perfuradas, uma rasgada e uma estourada quando pendurada no suporte, enquanto que, no GTB, em apenas duas luvas $(0,4 \%)$ foram encontrados furos. Esse achado reforça a afirmativa de Guandalini (1997), que encontrou, em caixa de 100 luvas ambidestras para procedimentos, $12 \%$ de luvas perfuradas e $5 \%$ com defeitos.

Fay e colaboradores (1995), Tucci (1996), Serratine, Pacheco e Miero (2007) orientaram que as luvas a serem utilizadas em procedimentos em áreas contaminadas devem estar perfeitas para ter seu uso efetivo.

Neste estudo, verificou-se que, com a grande deformação sofrida pelas luvas após duas horas não foi possível a observação de grande quantidade de furos, mesmo nas luvas com grandes deformações, mas que houve a saída de líquido, comprovando a permeabilidade do material testado, pois $100 \%$ da amostra apresentaram umidade superficial, e apenas uma luva apresentou vazamento que provocou mancha no papel absorvente. Pode-se observar que todas as luvas testadas sofreram pequenas deformaçōes e que, no grupo GTB, seis luvas apresentaram grandes deformaçóes. 
Tabela 1. Comportamento das luvas ao final de duas horas por grupos analisados.

\begin{tabular}{lccccc}
\hline Grupos & $\begin{array}{c}\text { Presença de } \\
\text { gotas observadas } \\
\text { a olho nu }\end{array}$ & $\begin{array}{c}\text { Presença de } \\
\text { pingos sobre } \\
\text { o papel }\end{array}$ & $\begin{array}{c}\text { Umidade } \\
\text { superficial }\end{array}$ & $\begin{array}{c}\text { Pequenas } \\
\text { deformaçóes } \\
\text { devido ao peso } \\
\text { do líquido }\end{array}$ & $\begin{array}{c}\text { Grandes } \\
\text { deformaçóes }\end{array}$ \\
\hline GTA 1 & 0 & 0 & 10 & 10 & 0 \\
GTA 2 & 0 & 0 & 10 & 10 & 0 \\
GTB 3 & 1 & 1 & 10 & 10 & 1 \\
GTB 4 & 0 & 0 & 10 & 10 & 5 \\
Total & 1 & 1 & 40 & 40 & 6 \\
\hline
\end{tabular}

\section{CONCLUSÃO}

Após a análise, foi possível afirmar que luvas de látex para procedimento são eficazes como EPI, porém o tempo de uso deve ser observado criteriosamente, pois há a possibilidade de permeabilidade após o uso prolongado, podendo haver contaminação do usuário. Assim, a observação criteriosa das luvas antes do seu uso, para a percepção de furos, é recomendada.

\section{Permeability analysis of latex gloves for procedure more used by dentistry pupils of the Federal University of Babia}

\section{Abstract}

The objective of this paper is to analyze the permeability of latex gloves, used by dentistry students of Federal University of Babia. Forty gloves from two different brands which were filled with water plus violet gentian were observed. After two hours they presented superficial damp.

Keywords: Glove - Permeability; Biosafety-Dental practice.

\section{REFERENNCIAS}

AGÊNCIA NACIONAL DE VIGILÂNCIA SANITÁRIA (Brasil). Resolução RDC no. 5, de 15 de fevereiro de 2008. Diário Oficial [da] República Federativa do Brasil, Poder Executivo, Brasília, DF, 18 fev. 2008.

BEZERRA, S.R.S.; PINHEIRO, J.T. Avaliação $\mathrm{da}$ integridade das luvas de procedimentos utilizadas na clínica endodôntica. R. Cons. Reg. Odontol. Pernamb., Recife, v.2, n.2, p.95-101, out. 1999.

CHECCHI, L. et al. Clinical significance of holes in gloves for dental use: a spectrophotometric analysis. Quintessence Int., Berlin,v.23, n.9, p.599-604, 1992.
CURY, A.F. Perfuração da luva cirúrgica: freqüência e prevenção de acidentes. R. Bras. Ginecol. Obstet., Rio de Janeiro, v.21, n.10, p.593-596, 1999.

FAY, M.F. et al. Gloves: new selection criteria. Quintessence Int., Berlin, v.26, n.1, p.25-29, 1995.

FREIRE, D.N. et al. Biossegurança: comportamento dos estudantes de Odontologia comparado aos seus conhecimentos e opiniōes. Arq. Odontol., Belo Horizonte, v.33, p.93, maio 1997. Supl.

GUANDALINI, S.L. Biossegurança. JBC: J. Bras. Clin. Odontol. Integrada, Curitiba, ano 1, n.1, p.9-11, jan./fev. 1997. 
INMETRO. Luva cirúrgica esterilizada $\&$ luva para procedimento não-cirúrgico nãoesterilizada. 1998. Disponível em: <http:// www.inmetro.gov.br/consumidor/produtos/ luvas.asp > Acesso em: 16 nov. 2007.

KATZ, J.N.; GOBETTI, J.P.; SHIPMAN JR, C. Fluorescein dye evalution of gloves integrity. J. Am. Dent. Assoc., Chicago, v.118, n.3, p.327-331, Mar. 1989.

LEAL, M.H.C. et al. Avaliação da integridade das luvas de procedimento utilizadas na clínica ortodôntica. RGO, Porto Alegre, v.52, n.4, p.251-255, out. 2004.

MELO, N.S.F. de O.; SMAHA, F. Prevalência de perfurações em luvas de procedimentos e luvas cirúrgicas. Pesq. Bras. Odontopediatr. Clín. Integr., João Pessoa, v.2, n.1, p.3-9, jan./ abr. 2002.
QUEIROZ, S.B.I.; RAMOS, R.Q.; BARREIRO, R.H. Avaliação da incidência de perfuração em luvas de procedimentos cirúrgicos. R. Bras. Patol. Oral, Natal, v.1, n.1, p.51-55, 2002.

RABELO, R.G. Biossegurança nas atividades de cirurgióes-dentistas. In: MANUAL de biossegurança. Salvador: Secretaria da Saúde do Estado da Bahia: Instituto de Ciências da Saúde da UFBA, 2001. pt.2, cap.10.

SERRATINE, A.C.P.; PACHECO, E.; MIERO, M. Avaliação da integridade das luvas cirúrgicas após a utilização em cirurgias odontológicas. ACM: Arq. Catarin. Med., Florianópolis, v.36, n.1, 2007.

TUCCI, M.G. Structural reactors of latex gloves in dental practice. Biomaterials, Oxford, v.17, n.5, p.517-522, 1996. 